\title{
Terrain modelling to derive a groundwater surface for NSW upland areas using the SRTM-S adaptively smoothed vegetation offset DEM
}

\author{
$\underline{\text { G.K Summerell }}^{\text {a }}$ and Mark Mitchell ${ }^{b}$ \\ ${ }^{a}$ NSW Office of Environment and Heritage PO Box 5336 Wagga Wagga NSW 2650 \\ ${ }^{b}$ NSW Office of Water PO Box 10 Wagga Wagga NSW 2650
}

Email: gregory.summerell@environment.nsw.gov.au

\begin{abstract}
Groundwater is a critical component of the hydrological cycle supporting and maintaining ecosystems, whether through direct access or indirectly through stream baseflow contributions. With growing pressures on water resources in NSW, more knowledge is needed in terms of depth of the watertable in the landscape. Currently NSW has large scale interpreted contour groundwater maps and spatially modelled surfaces based on dryland salinity data. This paper aims to describe the first stages in developing a more spatially explicit surface for groundwater, with improvements on predictions of groundwater depth. The study will encompass the coast, tablelands and ranges of NSW. The SRTM data used was the adaptively smoothed DEM with vegetation offsets removed (DEM-S) that was resampled to $50 \mathrm{~m}$ for the purposes of computational efficiencies $\left(\mathrm{DEM}-\mathrm{S}_{50}\right)$. The Multi resolution Valley Bottom Floor index was derived for the study area on a region by region basis. This layer was normalized, inverted and combined with the DEM-S $\mathrm{S}_{50}$. Both layers were then combined through direct multiplication. The result was a derived surface where MRVBF dominates in the large flat areas and the elevation dominates the hillslopes. The logic being that hillslope and alluvial hydrological processes are represented within the one surface. To develop a groundwater surface all groundwater bores with construction and water level information from each major river system catchment were used in a linear regression of a modelled surface fit to observed groundwater levels. The groundwater data available was from different years and tended to be biased towards alluvial water extraction areas. Given the large spatial area being involved the groundwater data was used to get the widest possible spatial coverage rather than selectively filtering the data to one water level sampling period as the number of samples than become to small. Once a fit to the groundwater data was created this was applied back to the modelled surface. To validate the model four sub catchments $(\sim 400-2000 \mathrm{~km} 2)$ spread across NSW were used. They had groundwater data throughout the catchment, captured within one sampling period. The validations showed $\mathrm{R}^{2}=0.27-0.44$. The FLAG UPNESS index is a published method used for determining implied groundwater surfaces and was used as a comparison. The UPNESS index achieved $\mathrm{R}^{2}=$ $0.08-0.12$ for the validation of large regional catchments. To improve the $\mathrm{R}^{2}$ further, geology, landuse and regolith cover relating to hydrology characteristics are planned as the next logical step. This study is critical in terms of the issues it aims to address but the groundwater data available to calibrate a modelled surface is the most restricting factor that not only impacts calibration but also validation confidence. Presently remote sensing products are being developed at the national and state scale to define areas in the landscape where vegetation is using stored water either from the soil profile or the water table. These products could provide valuable surrogate information in the future for calibration and validation of groundwater models to complement the sparse groundwater level information that exists.
\end{abstract}

Keywords: Groundwater, SRTM, hydrology, MRVBF, UPNESS. 


\section{INTRODUCTION}

The release of the Shuttle Radar Topographic Mission (SRTM) digital elevation data for Australia in 2005 created the opportunity for a substantial step forward in digital elevation models (DEMs) for the continent. (Dowling et. al, this conference). This new digital elevation model coverage is providing spatial resolution and subsequent better landscape definition than previously available from large spatial coverage data sources. In turn this has allowed the development of projects exploring methodologies previously not conceivable because of the lack of consistency in data sources. This study will focus on the development of a groundwater surface for the upland dominated areas of NSW (Figure 1). With growing pressures on our water resource availability in NSW, groundwater needs to be better understood in terms of depth of to the water table in the landscape. This is due to an increased awareness of the role it plays in maintaining and supporting ecosystems, whether through surface or subsurface access. Currently NSW has very coarse scale interpreted contour groundwater maps and more refined modelled surfaces to indicate hazards for salinity. The NSW Office of Water is presently completing a remote sensing project using MODIS to improve the level of knowledge of the location of terrestrial ecosystems that may have a reliance on groundwater. This project is being undertaken to provide a Statewide map of terrestrial ecosystems that potentially have a groundwater dependence, to assist in targeting future field based investigation and enable the monitoring of change. The identification of these ecosystems also enables their use in water management plans to place controls in order to manage water tables in the vicinity of high priority groundwater dependent ecosystems.

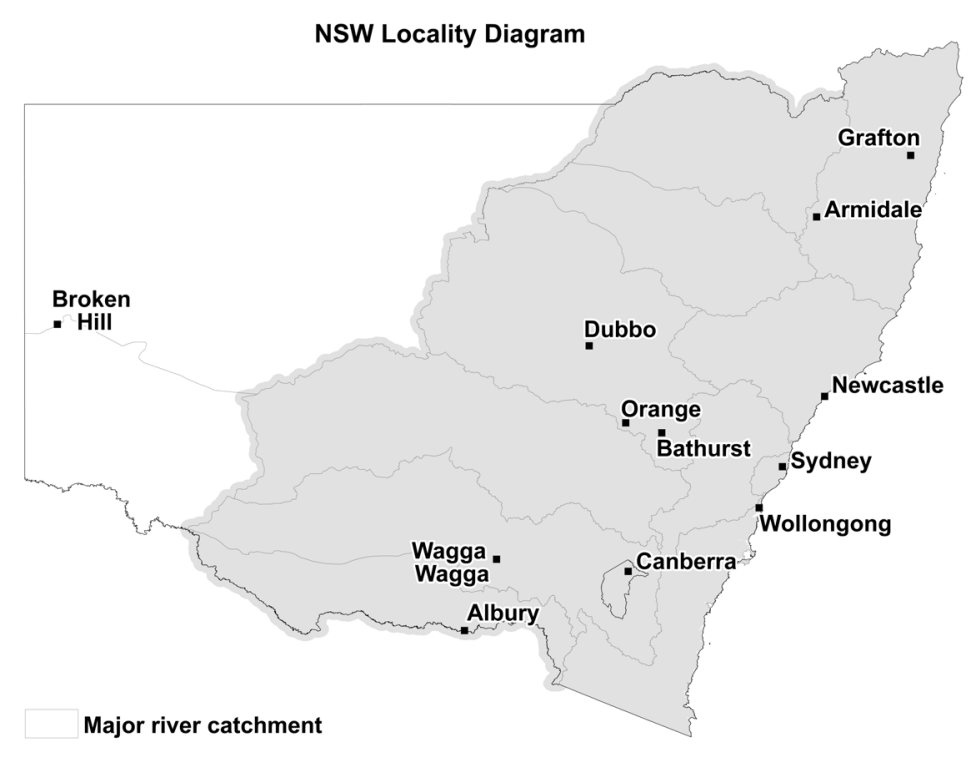

Figure 1. Study area extent within NSW shown in grey

\section{METHODS AND RESULTS.}

At the time of this study the SRTM that was the adaptively smoothed surface with vegetation offsets (DEMS) was available. The DEM-S extents were prepared into major regional river catchments (basins) and resampled using stand ArcGRID defaults to $50 \mathrm{~m}$ for the purposes of computational efficiencies (DEM- $\mathrm{S}_{50}$ ). Each basin DEM-S $\mathrm{S}_{50}$ was then normalized (DEM_n). Values closer to 1 were at the ridge tops and 0's at the alluvial flats.

$$
\text { DEM_n }=\text { STRM-S } 50 / \text { Maximum value of STRM-S } 50
$$

The Multi resolution Valley Bottom Flatness index (MRVBF) (Gallant and Dowling, 2003) was calculated for each STRM-S50 (MRVBFSTRM-S $5_{50}$ ) valley and the results normalized (MRVBF_n ) and inverted (MRVBFinv). Values closer to 1 were now also on ridgetops and 0 's were at alluvial flats. 
Summerell and Mitchell, Terrain Modelling to derive a groundwater surface for NSW upland areas

MRVBFinv $=$ absolute $\left(\right.$ MRVBF $\left.\_n-1\right)$

(3)

DEM $\mathrm{n}$ and the MRVBFinv were directly multiplied together to highlight areas of common or differing processes. Multiplication allowed MRVBF to dominate in the large flat areas and the elevation to dominate in the hillslopes. The resulting surface (WTVBF) allows hillslope and alluvial hydrology processes are represented in relation to each other.

WTVBF $=($ MRVBFinv1 * DEM_n1 $)$

The distribution of data in this study from MRVBF was classified into 8 or 9 classes as part of the normal processing from the algorithm. These classes therefore also express in the WTVBF. The WTVBF and groundwater levels for all groundwater bores in the region that had construction and water level information were where used for calibrating the WTVBF. The groundwater data available was from different years and tended to be biased to alluvial water extraction areas. Table 1 shows the number of groundwater bores per major river catchment (Figure 2).

Table 1. Number of Groundwater bores used in analysis across major river catchment

\begin{tabular}{|c|c|}
\hline NSW Major River Catchments (Figure 3) & $\begin{array}{c}\text { Groundwater } \\
\text { bore Samples }\end{array}$ \\
\hline Murray and Murrumbidgee & 2256 \\
\hline Lachlan & 4109 \\
\hline Central West & 2825 \\
\hline Namoi & 3594 \\
\hline Board Rivers Gwydir & 1745 \\
\hline Northern Rivers & 2246 \\
\hline Hunter -Central Rivers & 1139 \\
\hline $\begin{array}{c}\text { South Rivers, Hawkesbury Nepean, Sydney } \\
\text { Metro }\end{array}$ & 2768 \\
\hline
\end{tabular}

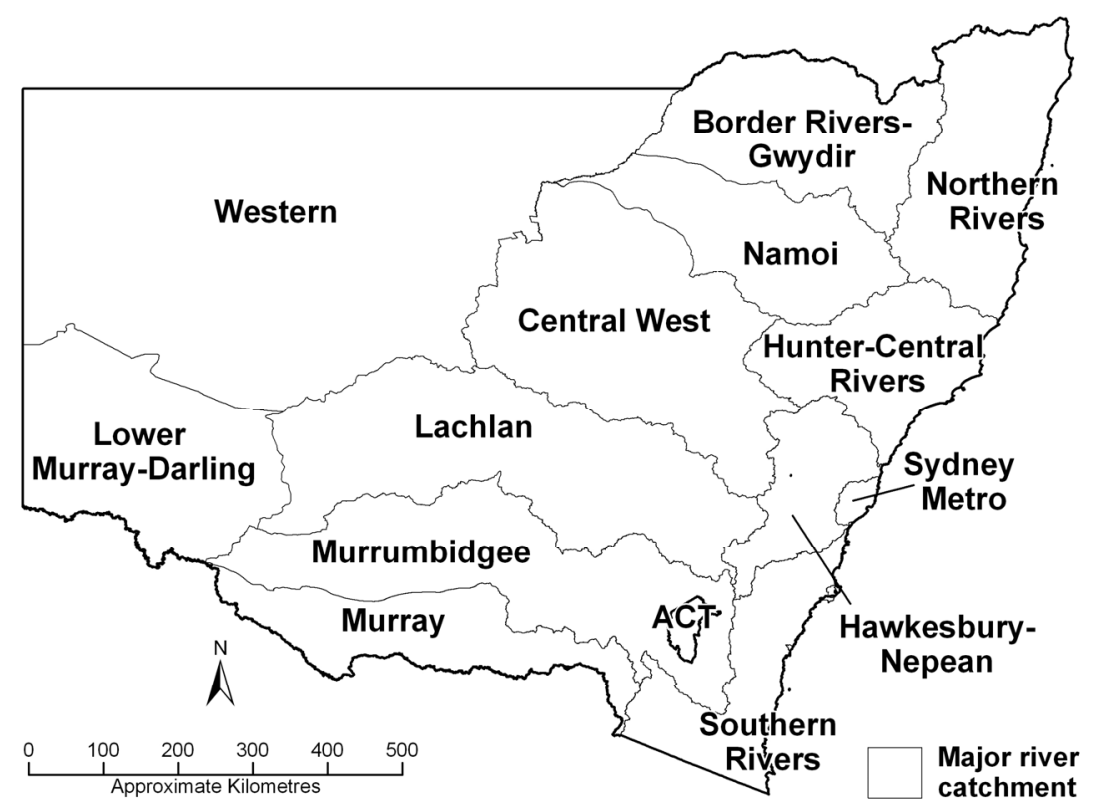

Figure 2. Major river catchments from Table 2. 
The 8 or 9 classes (Dependant on major river basin) of MRVBF were used to classify the water table data. The natural surface (NS) and the depth to water table (WT) elevations in Australian Height Datum were charted against the WTVBF index. The linear trend line and equation was then determined for the natural surface and water table for each of the classes of MRVBF (Figure 3).

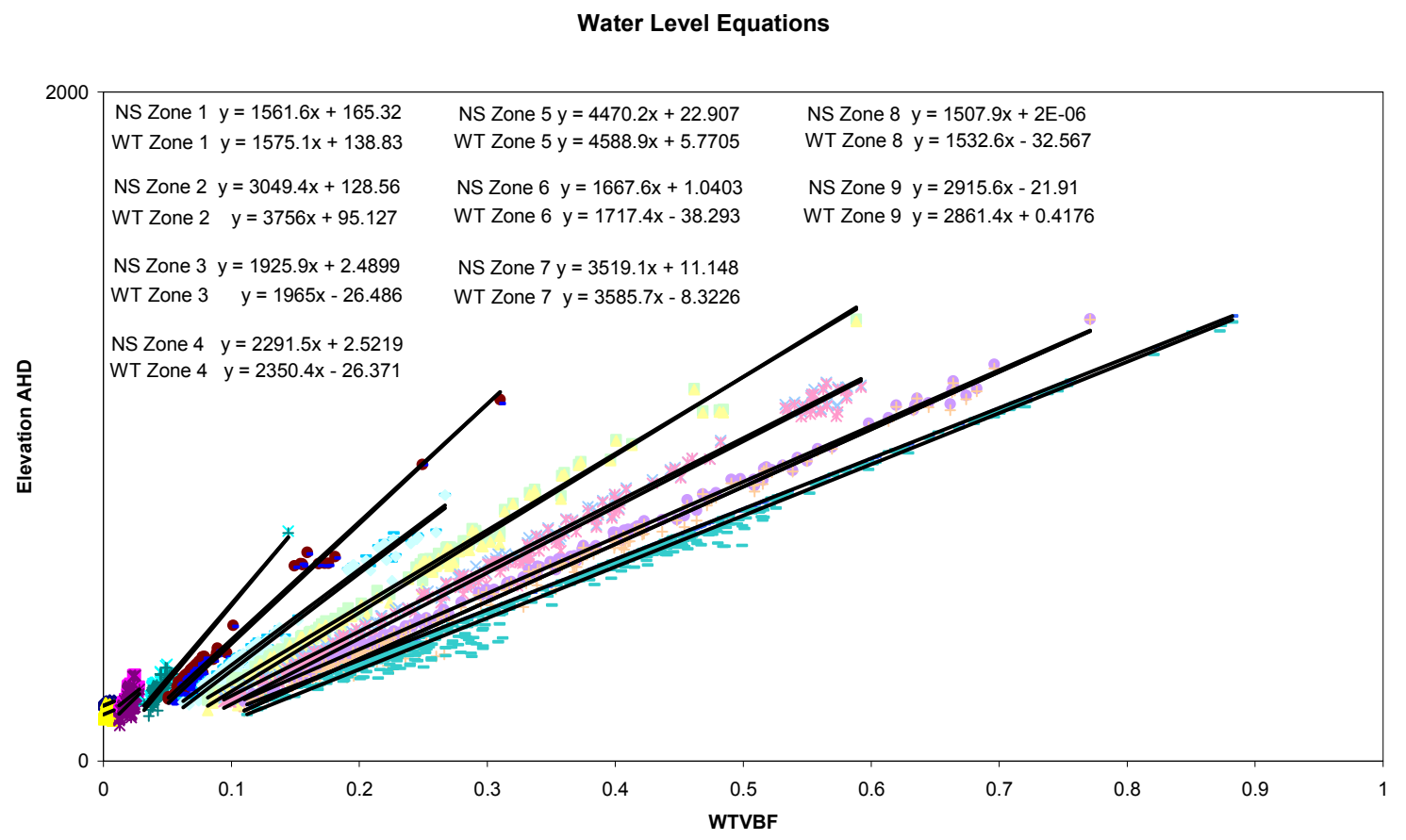

Figure 3. An example from the Lachlan River catchment showing the linear water level equations fitted to each of the 9 classes. This assessment was applied to each regional catchment.

The WTVBF index was classified into the corresponding classes and the linear equation for the Natural Surface and Water Table surface applied. Values of ' $a$ ' and ' $b$ ' were obtained from Figure 3 for each class.

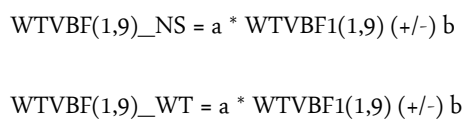

The WTVBF(1,9)_NS and WTVBF $(1,9)$ _WT were then subtracted from each other by their absolute values (to avoid occasional negative values) to create a depth of water table from ground surface. This was defined as the parallel water table fit was repeated for all 9 classes and then grids 1 to 9 were merged using standard arcGRID default parameters.

Par_NS(1,9)_WT(1,9) = abs(WTVBF(1,9)_NS) - absolute(WTVBF(1,9)_WT $)$

(7)

The lower and upper values for the water table depth were determined based on all the bores sampled within each of the 9 classes for each major river catchment. The lower value was based on the fifth percentile of values and the upper water table value was based on 0.5 of the standard deviation above the mean. Separate methods were used to determine the water table range because 0.5 of the standard deviation of the mean was influenced by the deeper water table depths. The influence of the deeper water table depths is because the bias in the data caused by the water table information being based on bore construction reports, which document the depth of the first water bearing zone rather than the first indication of intersecting the water 
table. The data is also the collation of the total record which would be influenced by the temporal variability in water table levels. This caused the mean to be a relatively deep water table value, when the proportion of shallow water table levels was greater. The range of values for each valley's groundwater level data was then applied back to the parallel fit water table data for each class.

$$
\text { par_fit }(1,9)=\text { a * Par_NS(1,9)_WT1 }(1,9)(+/-) \text { b }
$$

The process in (8) was termed the final fit and all 9 classes were merged together using default arcGRID parameters to create a Derived Water Table surface (DWT).

\subsection{Validation}

Four catchments $\left(\sim 400-2000 \mathrm{~km}^{2}\right)$ that had good groundwater levels for one sampling period were used for validation. These catchments were the Kyeamba and Tarcutta catchments in southern NSW, the Little River catchment in central NSW and the Alstonville catchment in northern NSW (Figure 4). For each of these catchments the groundwater level data was compared to the DWT. Summerell et. al. 2004 published a method of using the FLAG UPNESS index (also derived from digital elevation data) to model near surface groundwater levels on localized hillslopes. The FLAG UPNESS index was also calculated to compare with the DWT (Table 2).

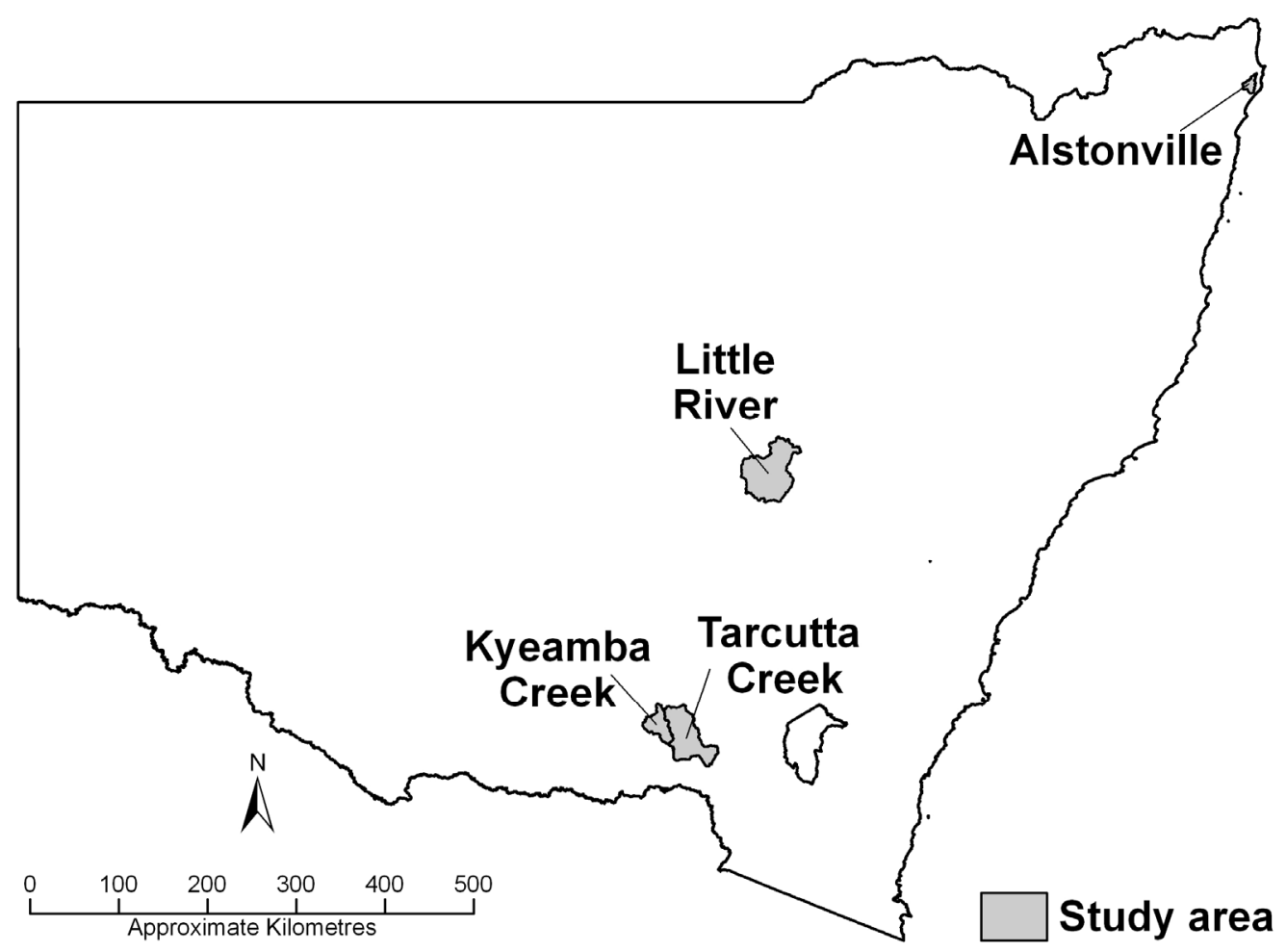

Figure 4. Location of validation catchments.

Table 2. Correlation of observed water level data with DWT and FLAG UPNESS indices

\begin{tabular}{|c|c|c|}
\hline Catchment & $\mathbf{R}^{2}$ DWT & $\mathbf{R}^{2}$ FLAG UPNESS \\
\hline Kyeamba & 0.30 & 0.11 \\
\hline Tarcutta (alluvial) & 0.27 & 0.12 \\
\hline Little River & 0.44 & 0.08 \\
\hline Alstonville & 0.36 & 0.10 \\
\hline
\end{tabular}




\section{DISCUSSION AND CONCLUSIONS}

Figure 5 shows the resulting DWT surface of all major river catchments after they have been merged. Edge effects between catchments occur usually at highland catchment boundaries. This is because fewer groundwater bores exist in these areas creating more errors in final fits to observed water levels. The methodology has improved the ability to model water table levels based on actual water level data and landscape characteristics. The ability to model water table levels is inherently complex due to other factors other then topography driving water levels. But for the water level data that does exist the majority of bores are constructed in water bearing zones lower in the landscape used for purposes such as stock and domestic requirements. Therefore representation of groundwater level data across the landscape often does not exist.

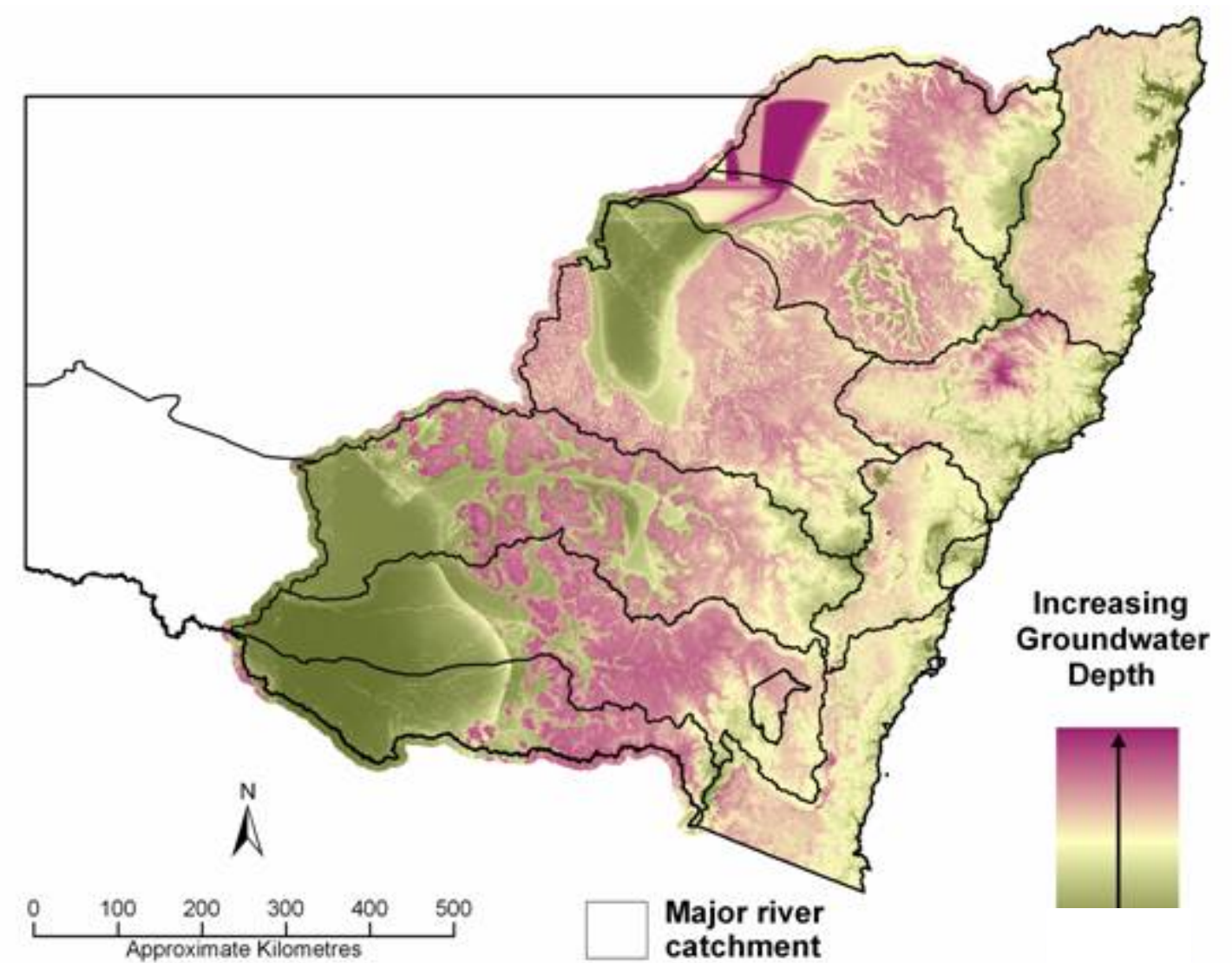

Figure 5. Derived groundwater surface for major upland basins of NSW.

The $\mathrm{R}^{2}$ could be further improved if there was more consistent information temporally and spatially on the water table level. Future work will test the benefits of stratifying the study area based on typical catchment features such as zones representing geology, landuse and regolith cover properties as each of these influence hydrological processes.

The new digital elevation model from the STRM provides larger spatial coverage ( 7 millions $\mathrm{km}^{2}$ ), at high resolution giving subsequent better landscape definition. In turn this has allowed the development of projects exploring methodologies previously not conceivable in Australia.

The level of groundwater level information is not going to rapidly increase therefore remote sensing products are being explored to provide surrogate information on groundwater. For example remote sensing products are being developed at the national and state scale to define areas in the landscape where vegetation is using stored water either from the soil profile or the water table. 
Summerell and Mitchell, Terrain Modelling to derive a groundwater surface for NSW upland areas

\section{ACKNOWLEDGMENTS}

This project was completed with the assistance of funding from Catchment Action NSW, an initiative of the NSW Government to improve natural resource management knowledge and implementation. Sandy Grant from the Office of Environment and Heritage for helping with data preparation and figure presentation.

\section{REFERENCES}

Dowling, T.I, Matthew B, Read A.M, and Gallant J.C. (This conference) Assessing continental drainage divisions using the 1 second $(30 \mathrm{~m})$ resolution Shuttle Radar Topographic Mission DEM of Australia.

Gallant, J.C., and Dowling, T.I., 2003. A multi-resolution index of valley bottom flatness for mapping depositional areas, Water Resources Research, 39, No. 12, 1347, doi 10.1029/2002WR001426.

Summerell G.K, Dowling T.I, Wild J.A and Beale G (2004) FLAG UPNESS and its application for determining seasonally wet and waterlogged soils. Australian Journal of Soil Research 42 155-162. 